\title{
Motivation in Nursing Management
}

\author{
S. Josphine Vinitha ${ }^{1}$, Dr. Jenardhanan ${ }^{2}$ \\ ${ }^{1}$ Vice Principal/Professor, NIMS College of Nursing, Aralummoodu, Neyyatinkara, Trivandrum-695123 \\ ${ }^{2}$ Director of Management Studies, NICHE, Kumaracoil
}

Corresponding Author: S. Josphine Vinitha

DOI: https://doi.org/10.52403/gijash.20220104

\begin{abstract}
Motivation is a critical part of nursing leadership as nurses need to understand patients, family and communities to gain valued outcomes like improved patient outcomes and quality of nursing care standards. Motivation in nursing management parts the nursing professionals in to action, improves friendly relationship and leads to stability of work force. Motivation in Nursing Management is a powerful energy that drives and excites nursing professionals which results in their maximum contribution. Nursing leadership is one of the single most important factors in motivating and inspiring and inspiring nurses to care for individuals, enhance communication skill, problem solving and commitment to patient advocacy motivated nurses stay with a task long enough to achieve the goals. The effective direction, motivation and leadership, takes a nursing department forward. The attributes of good interpersonal relationship, mentorship and role modelling tend to move evident when the nurse leaders are highly assertive, accountable and motivated.
\end{abstract}

Key words: Motivation, Nursing, Leadership, Management, Attributes.

\section{INTRODUCTION}

Man is goal directed and his behavior is motivated by desire to attain some goal. Motivation is a concept used to describe both the extrinsic conditions that stimulate certain behavior and the intrinsic responses that demonstrate that behavior in human beings. The intrinsic response is sustained by sources of energy called motives often described as needs, wants or drives. All people have motives and recorded as behavior. The 4th phase of management process is directing also called coordinating or activating in directing managers sets plans in to action, which needs creation of a motivating environment. The amount and quality of work accomplished by managers reflects their motivation and motivation of their subordinates. So it is essential for a manager to know, what motivates people. De motivated managers themselves will affect the subordinates in a negative way.

\section{Meaning}

The term motivation derives from Latin word-'movere' which means to move. Thus motives are movers or goals to an action. Motivation is the process by which behavior in mobilized and sustained is a particular direction.

\section{Definition}

1. Motivation is the force within the individual that influence strength or direction of behavior (mills 1998). Because motivation comes from within the person, the humanistic manager creates a motivating climate.

2. Work motivation in a set of energetic forces that originated both within as well as beyond an individual's being to initiate work related behavior and to determine to form direction, intensity and duration. (Craigpinder)

3. Motivation refers to the way is which urges, drives, desires, aspirations, strivings or needs influence the choice of alternatives in the behavior of human beings (MC Farland) 


\section{Components of Motivation}

1. Motives-These are needs, wants, drives or impulses operating within the man. Motives are 'whys' of behavior. They initiate activity and determine the direction of the behavior.

2. Goals-These are outside the individual and often called incentives or rewards.

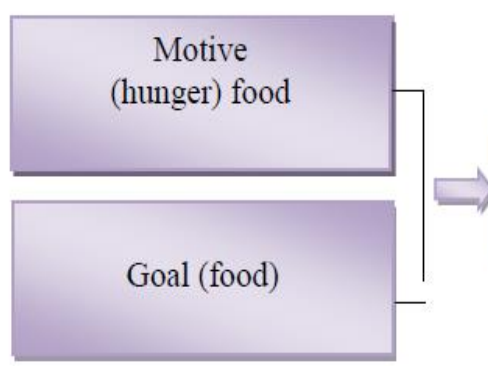

Berd son and Steiner described 'motive'-as an inner state that energize activity or moves and that directs or channels behavior towards goals.

Kuontg and O'Donnell have described it as need-want-satisfaction chain.

\section{Need-want-satisfaction chain}

3. Goal directed activity-It is a motivated behavior directed at reaching a goal.

Thus motive along with goal produces behavior which may be either goal-directed or goal activity. The relationship between situation is as follows.

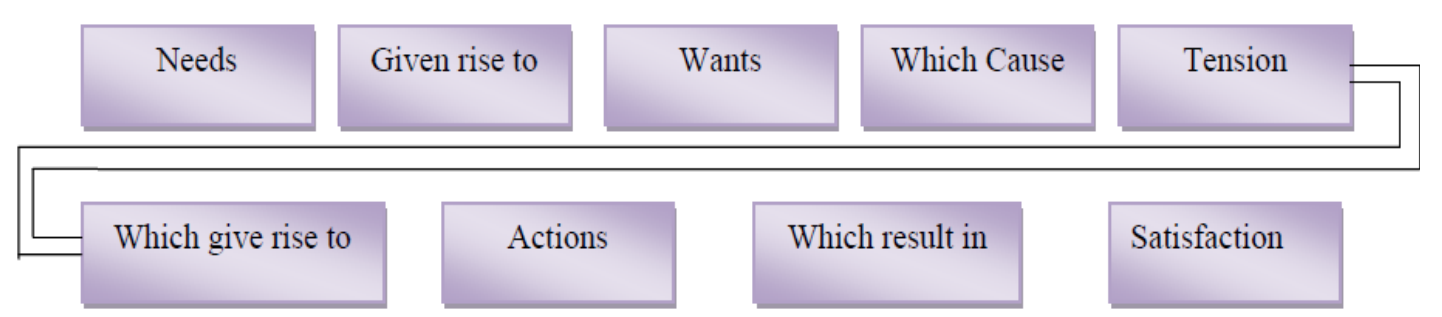

\section{Nature or characteristics of Motivation}

1. Energetic force- Motivation energies, directs and sustain human behavior. It is a desire and enthusiasm to act and urge to accomplish a task. This force can originate 'within' or 'beyond' an individual.

2. As internal feeling- Motivation is mainly psychological. It relates to those forces within the individual and directs to act in certain ways. It is related with needs, drives, desires, tensions and motives which are mental states.

3. Goal-directed behaviour- Motivation is a reported urge or tension to move in a given direction or to achieve certain goal.

4. Either positive or negative- Motivation can be positive or negative. Positive motivation is based on rewards like pay,
The chain starts with felt needs, resulting in wants and goals sought. These unfulfilled desires create tension which causes action towards achieving goals and in the end satisfying needs.

Need-want-satisfaction chain
Goal activity

(eating food) praise, pride, participation etc. Negative motivation uses punishment. It is based on force of fear. Depending on the situation, both are used organization.

5. Person to totality is motivated-not-inpart Each employee is a self contained, and inseparable unit and all his needs are interrelated. He can be motivated with total zeal enthusiasm.

6. Individuals differ in their motivationMan is motivated by different factors- as variety of needs and desires which are different for different persons.

7. Motivation is not always conscious and visible -Only a small part of mind is conscious and visible. This is why men cannot verbalize his motivation to achieve certain goals.

8. Motivations change-Motivation of each individual change from time to time. As 
one need is satisfied. It is replaced by other unsatisfied need, people's, wants change their behavior.

9. Individual Phenomenon-Motivation is highly individualistic. No two people are alike. Different people differ in their needs, aspirations, backgrounds and they rank things differently. Thus management's role is to create a work climate in which persons with different needs and personalities can remain motivated.

10. Motivation is more than more techniques-Motivation is more than application of specific techniques. It is a philosophy based on the needs and desires of employees.

11. Process oriented-M.R. Jones says that motivation is process oriented and concerns behavioral choice, direction, goals and the rewards received for performing.

12. Complex process-It is difficult to explain and predict the behaviour of employees. A manager has to understand and satisfy multiplicity of human needs.

13. Motivation is not equated with behaviour-Though motivation is intertwined with behaviour, it is not synonymous with behaviour.

14. Essence of performance-Although factors like ability, resources, and conditions of performance are important, without motivation these cannot produce good result. Motivation is also a kind of resource.

15. Motivation can 'escape' overtimeMotivation is in short supply and it demands a continuous replenishment. Hence the motivational effort should never end.

16. The process of motivation-The motivational process is circular as it repeats in a cycle and include.

\section{Need deficiency}

Need is a deficiency within man. It provides a spark which begins the sequence of behaviour. An unsatisfied need cause physical or psychological tension within the individual. It is an energizer within the individual to trigger the behavioural responses.

\section{Search of Means}

People seek means to reduce need deficiencies and thereby reduce tension.

\section{Goal directed behaviour}

Their activity is directed towards goal. They select a course of action and thus an outcome directed behaviour occurs.

\section{Assessment}

After a period of time managers assess and evaluate the goals accomplished.

\section{Rewards punishments}

The performance evaluation results in type of reward or punishment. Manager offers something valuable to the person for good work other hand provide negative motivation of performance is un acceptable.

\section{Re evaluation of situation}

The process is completed when the person weights the outcome and re evaluate the needs and demands. He evaluates the extend of satisfaction obtained and make changes about that behaviour to follow. Discovery of changes starts and this in turn trigger the process.

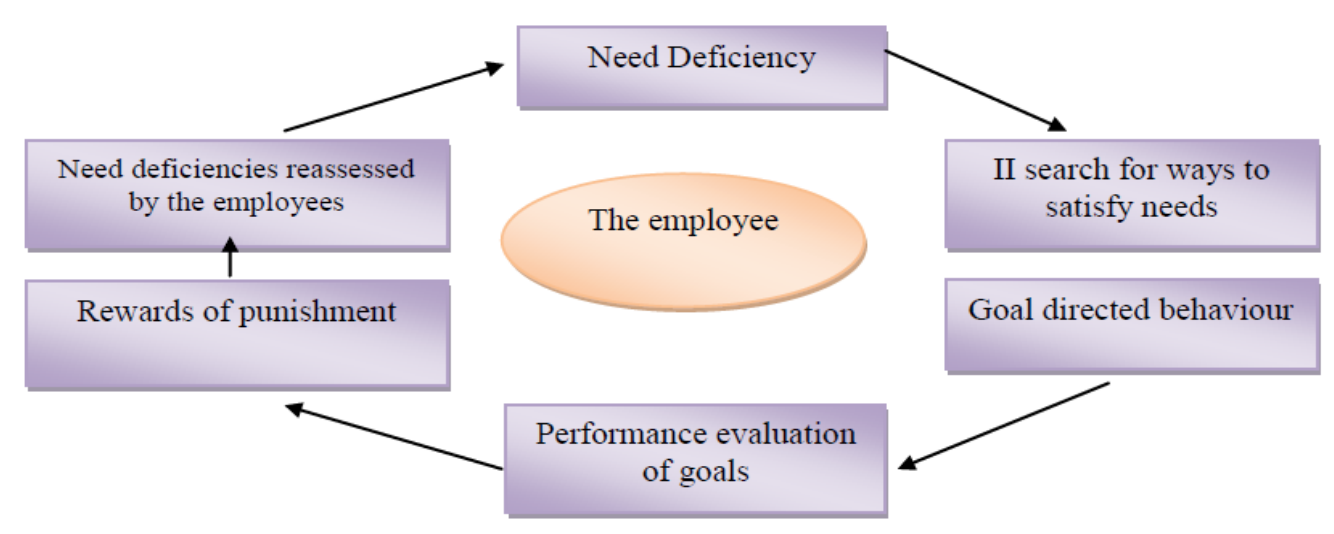


Objectives or purposes of motivation in an organization

1. To stimulate the employees to perform effectively

2. The channelize behaviour into specific course

3. To understand individual's motives needs and aspirations

4. To encourage employees to stay with the organization

5. To predict, to change and even to control future behaviour

6. To create enthusiasm, initiative and loyalty

7. To direct and sustain behaviour towards the accomplishment of organizational goal.

8. Effective utilization of resources financial, physical and human of the organization.

9. To raise the morale and level of satisfaction of the employees.

10. To build good human relations and team work.

\section{Types of motivation}

\section{Motivation can be classified as follows}

\section{Negative and positive motivation}

Negative motivation is based on

force, fear and threats. The fear of punishment or unfavorable consequences affect the behavior of employees. People may be threatened with punishment the pay cut, money penalty, demotion, lay of etc to set the work done.

Researchers found that, negative motivation can produce results for short period only. Likert suggest that long run negative motivation reduces employee cooperation, loyalty and unity. It creates frustration and hostile state of mind among employees.

Positive motivation is based upon rewards, recognition and appreciation of work. It provides gain and benefits.

Positive motivation improves the standards of performance, and leads to a good team spirit and pride. It results in a sense of cooperation belonging ness and happiness.
Positive motivation includes responsibility placement, high standards, self control and participation of worker as a responsible citizen in the community.

\section{Extrinsic and Intrinsic motivation}

Extrinsic motivation is induced by external factors like wages, fringe benefits, insurance plans, profit sharing, health and medical services, vacations etc. these incentives are often associated with financed rewards and remain outside the work activity. They are provided at the time of performance of work. According to Herzberg there are "maintenance or hygiene" factors, that prevent dissatisfaction and their presence does not lend feelings of satisfaction.

Intrinsic motivations are those which occur at the time of doing work. They provide satisfaction during the work activity itself. They are related to with accomplishment of something worthwhile. They seek to satisfy higher level needs of men.

These are usually non financial rewards like praise, recognition etc.

\section{Financial and Non financial Motivation}

Financial motivators are 'pecuniary' in nature and are associated directly or indirectly with money, wages, and salaries are the direct financial incentives.

Indirect financial incentive are bonuses, profit sharing, retirement benefits, vacation pay, health insurance, free medical services or other benefit which involve flow of money from organization to its employees. Most of the physical needs are satisfied through money and hence 'money' is one of the most powerful motivation. In motivation society, money serves as a symbol of success and achievements. Money is often recognized as a basis of status, respect and power. It enables a man to satisfy his social and egoistic needs.

Non financial motivators are those which are on the whole, not directly related to with money. Such motivators are praise, 
higher responsibility, participation in decisions, authority, job satisfaction etc.

Dubin says Non financial incentives are the psychic rewards

Features of non financial motivators are

1. They are intangible incentives

2. They are meant for the satisfaction of those needs which cannot be satisfied with money.

3. They satisfy the higher needs like egoistic and self actualization needs. They are used to motivate managerial personnel. They are based on the nature of jobs, and aspirations and urges of employees.

4. They are based on the nature of jobs, and aspirants and urges of employees.

5. They have an indirect influence on the organization and the members.

Leadership roles associated with creation of motivating work climate

1. Recognize each worker as a unique individual who is motivated by different things.

2. Identifies the individual and collective value system of the unit and implements a reward system which is suitable.

3. Listen attentively to individual of collective work values and attitudes to identify the un met needs that can cause dissatisfaction.

4. Encourage workers to "stretch" themselves to promote self growth and self actualization.

5. Maintain as positive and enthusiastic image as a role model to subordinates.

6. Encourage mentoring, sponsorship and coaching with subordinates.

7. Devote time and energy to create an environment that is supportive and encouraging to the discouraged individual.

8. Develop a unit philosophy that recognize the unique worth of each employee and promotes reward system.

9. Demonstrate a belief in subordinate through actions and words.
10. Self aware regarding own enthusiasm for work and takes steps to remotivate self as needed.

Losoney (1977) identified some characteristics of the encouraging manager that are essential for motivating climate. They are

1. An encouraging manager sees only individuals in the world. When faced with groups of people, each person is viewed as unique, with interest, problems and goals that must be acknowledged.

2. The encouraging person is safe, totally accepting person. He/she believes that the discouraged person not consistently experience safe relationship and hence develop a mask.

3. An encouraging person has faith in human nature and has faith in discouraged person.

4. The person is sincerely enthusiastic about the growth of discouraged persons and communicates enthusiasm to others.

5. He will be ultra-sensitive to the self defeated person's goals, values and purposes, and believes that each behavior is significant and consequential.

6. The encouraging person realize that knowledge of discouraged person's past proud moments- to build a new and more positive identity.

7. $\mathrm{He} / \mathrm{she}$ is sensitive to over dependency in the relationship and helps the discouraged person to develop self encouragement.

In addition to positive reinforcement, role modeling and additional strategies include.

1. Have clear expectations for workers and communicate these expectation effectively

2. Be fair and consistent when dealing with employees.

3. Be a firm decision maker using an appropriate decision making style. 
4. Develop the concept of team workdevelop group goals and projects that will build a team spirit.

5. Integrate the staffs needs and wants with the organization interests and purposes.

6. Know the uniqueness of each employer and let each employee to understand themselves.

7. Remove traditional blocks between the employee and the work to be done.

8. Provide experiences that challenge the employee and allow opportunity to grow.

9. Request participation and input from all subordinates in decision making when appropriate.

10. Give credit and recognition to the subordinates, whenever possible.

11. Be sure that employees understand the reason behind decision and actions.

12. Reward desirable behaviours and be consistent in handling undesirable behavior.

13. Let the employees for individual judgment as much as possible.

14. Create a trustful and helping relationship with employees.

15. Let employees exercise as much control as possible over their work environment.

16. Be a role model for employees.

\section{CONCLUSION}

To achieve the nursing and organizational goals, the nurse manager requires brilliance and sensitivity to people, energy and negotiating skills, gaining people's attention so that their aspirations and emotion are mended with those of a leader, the profession and the organization for which they work.

Nurse leaders should do motivational research and should be aware of findings of motivational research, so that they can apply it to personal management. Nurse should have the intellectual skills that open her minds, to analyze their perceptions and synthesis of their perceptions with those of leadership. For this the nurse needs mental stability, emotional intensity and communication and negotiation skills

\section{Acknowledgement: None}

\section{Conflict of Interest: None}

\section{Source of Funding: None}

\section{REFERENCES}

1. Stover JB, Iglesia G, Boubeta AR, Liporace MF. Academic motivation scale: Adaptation and psychometric analyses for high school and college students. Psychol Res Behav Manag. 2012;5:71-83

2. Alt D. College students' academic motivation, media engagement and fear of missing out. Comput Human Behav. 2015;49: 111-19.

3. Vecchione M, Alessandri G, Marsicano G. Academic motivation predicts educational attainment: Does gender make a difference. Learn Individ Differ. 2014;32:124-31.

4. BrÁten I, Olaussen BS. The motivational development of Norwegian nursing students over the college years. Learn Health Soc Care. 2007;6:27-43.

\section{Author's Biography}

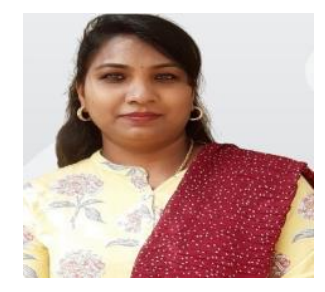

\section{S. Josphine Vinitha}

Vice Principal/Professor, NIMS College of Nursing, Aralummoodu, Neyyatinkara, Trivandrum-695123

How to cite this article: S. Josphine Vinitha, Jenardhanan. Motivation in nursing management. Galore International Journal of Applied Sciences \& Humanities. 2022; 6(1): 22-27. DOI: https://doi.org/10.52403/gijash. 20220104 